\title{
Papers
}

\section{Human albumin administration in critically ill patients: systematic review of randomised controlled trials}

\author{
Cochrane Injuries Group Albumin Reviewers
}

\begin{abstract}
Objective: To quantify effect on mortality of administering human albumin or plasma protein fraction during management of critically ill patients. Design: Systematic review of randomised controlled trials comparing administration of albumin or plasma protein fraction with no administration or with administration of crystalloid solution in critically ill patients with hypovolaemia, burns, or hypoalbuminaemia.

Subjects: 30 randomised controlled trials including 1419 randomised patients.

Main outcome measure: Mortality from all causes at end of follow up for each trial.

Results: For each patient category the risk of death in the albumin treated group was higher than in the comparison group. For hypovolaemia the relative risk of death after albumin administration was 1.46 (95\% confidence interval 0.97 to 2.22), for burns the relative risk was 2.40 (1.11 to 5.19), and for

hypoalbuminaemia it was 1.69 (1.07 to 2.67). Pooled relative risk of death with albumin administration was 1.68 (1.26 to 2.23). Pooled difference in the risk of death with albumin was $6 \%$ (95\% confidence interval $3 \%$ to $9 \%$ ) with a fixed effects model. These data suggest that for every 17 critically ill patients treated with albumin there is one additional death.

Conclusions: There is no evidence that albumin administration reduces mortality in critically ill patients with hypovolaemia, burns, or hypoalbuminaemia and a strong suggestion that it may increase mortality. These data suggest that use of human albumin in critically ill patients should be urgently reviewed and that it should not be used outside the context of rigorously conducted, randomised controlled trials.
\end{abstract}

\section{Introduction}

In patients with acute and chronic illness serum albumin concentration is inversely related to risk of death. A systematic review of cohort studies meeting specified criteria estimated that for each $2.5 \mathrm{~g} / 1$ decrement in serum albumin concentration the risk of death increases by between $24 \%$ and $56 \%{ }^{1}$. The association persists after adjustment for other known risk factors and pre-existing illness, and some commentators have suggested the possibility of the albumin molecule hav- ing a direct protective effect. ${ }^{1}$ Partly as a result of the association between serum albumin and mortality, human albumin solutions are now used in the management of a diverse range of medical and surgical problems. Licensed indications for human albumin solution are the emergency treatment of shock and other conditions in which restoration of blood volume is urgent, the acute management of burns, and clinical situations associated with hypoproteinaemia. $^{2}$

Compared with other colloidal solutions and with crystalloid solutions, human albumin solutions are expensive. ${ }^{3}$ Volume for volume, human albumin solution is twice as expensive as hydroxyethyl starch and over 30 times more expensive than crystalloid solutions such as sodium chloride or Ringer's lactate. Because of the high cost and limited availability of human albumin, it is imperative that its use should be restricted to the indications for which it has been shown to be effective. To quantify the effect on mortality of human albumin solution in the management of critically ill patients with hypovolaemia from injury or surgery, burns, and hypoproteinaemia, we conducted a systematic review of randomised controlled trials.

\section{Methods}

\section{Identification of trials}

Our aim was to identify all relevant randomised controlled trials that were available for review by March 1998. A randomised controlled trial was defined as a trial in which the subjects followed were assigned prospectively to one of two (or more) interventions by random allocation or some quasirandom method of allocation. This definition was agreed at an international meeting held in Oxford in November 1992 in association with the official opening of the UK Cochrane Centre. We sought to identify all randomised controlled trials of administration of human albumin or plasma protein fraction (supplemental albumin or plasma protein fraction compared with no albumin or plasma protein fraction or with a crystalloid solution) in critically ill patients with hypovolaemia from trauma or surgery, with burns, or with hypoalbuminaemia. Studies that compared different levels of albumin supplementation were also included.
Editorial
by Offringa and
Letters p 277
Cochrane Injuries
Group, Department
of Epidemiology
and Public Health,
Institute of Child
Health, London
WC1N 1EH
Ian Roberts,
director, child health
monitoring unit
Ian.Roberts@ich.ucl.
ac.uk
BMJ 1998;317:235-40 
Trials were identified by computerised searches of the Cochrane Controlled Trials Register, Medline, Embase, and BIDS Index to Scientific and Technical Proceedings (search strategies are available from IR); by hand searching 29 international journals and the proceedings of several international meetings on fluid resuscitation; by checking the reference lists of all included trials; and by contacting the authors of identified trials and asking them about any other published or unpublished trials that may have been conducted. There were no language restrictions. To identify unpublished trials we searched the register of the Medical Editors' Trial Amnesty, ${ }^{4}$ and contacted the
Medical Directors of Bio Products Laboratory (Zenalb), Centeon (Albuminar), and Alpha Therapeutic UK (Albutein).

Outcome measures and data extraction

The outcome measure was mortality from all causes at the end of the follow up period scheduled for each trial. For all trials we collected data on the type of participants, details about the interventions, the quality of concealment of allocation, and mortality at the end of follow up. We rated quality of allocation concealment using the method proposed by Schulz et al. ${ }^{5}$ We sought mortality data in simple categorical form, and we did

\begin{tabular}{|c|c|c|c|c|c|c|c|}
\hline Trial & Critical illness & $\begin{array}{l}\text { No of } \\
\text { patients }\end{array}$ & Intervention & Control & $\begin{array}{l}\text { Length of } \\
\text { follow up }\end{array}$ & $\begin{array}{l}\text { Total No } \\
\text { of deaths }\end{array}$ & $\begin{array}{l}\text { Allocation } \\
\text { concealment }\end{array}$ \\
\hline \multicolumn{8}{|l|}{ Hypovolaemia } \\
\hline Skillman et a ${ }^{31}$ & Surgery & 16 & $\begin{array}{l}25 \% \text { concentrated salt-poor albumin } \\
1 \mathrm{~g} / \mathrm{kg} \text { and } 5 \% \text { albumin in saline }\end{array}$ & Ringer's lactate with $5 \%$ dextrose & 1 day & Not known & 2 \\
\hline Shah et $\mathrm{al}^{27}$ & Trauma & 20 & $\begin{array}{l}5 \% \text { salt-poor albumin in Ringer's } \\
\text { lactate }\end{array}$ & Ringer's lactate & Unspecified & 5 & 3 \\
\hline Boutros et al ${ }^{9}$ & Surgery & 24 & Albumin in $5 \%$ dextrose & $\begin{array}{l}5 \% \text { dextrose in lactated Ringer's }(n=9) \\
5 \% \text { dextrose in } 0.45 \% \mathrm{NaCl}(n=8)\end{array}$ & 4 days & 2 & 2 \\
\hline Virgilio et a $\left.\right|^{33}$ & Surgery & 29 & $5 \%$ albumin in Ringer's lactate & Ringer's lactate & $21 / 2$ weeks & 2 & 2 \\
\hline Lucas et $\mathrm{al}^{21}$ & Trauma & 52 & $\begin{array}{l}150 \mathrm{~g} \text { salt-poor albumin during } \\
\text { operation, } 150 \mathrm{~g} / \text { day for } 5 \text { days } \\
\text { postoperatively }\end{array}$ & No albumin & $\begin{array}{l}\text { To positive fluid } \\
\text { balance or oral } \\
\text { intake }\end{array}$ & 7 & 1 \\
\hline Zetterstrom et $\mathrm{a}^{37}$ & Surgery & 30 & $\begin{array}{l}20 \% \text { albumin } 100 \mathrm{ml} \text { at end of } \\
\text { operation, } 200 \mathrm{ml} \text { on day of operation, } \\
100 \mathrm{ml} / \text { day for next } 3 \text { days }\end{array}$ & No albumin & Unspecified & 1 & 3 \\
\hline Grundman et a $\left.\right|^{17}$ & Surgery & 17 & Human albumin and crystalloid & Crystalloid only & 5 days & 1 & 2 \\
\hline Rackow et al ${ }^{30}$ & Trauma and sepsis & 17 & $5 \%$ albumin & $0.9 \% \mathrm{NaCl}$ & To discharge & 12 & 2 \\
\hline Gallagher et $\mathrm{al}^{12}$ & Surgery & 10 & $5 \%$ albumin & Ringer's lactate & 1 day & 0 & 3 \\
\hline Nielsen et $\mathrm{al}^{23}$ & Surgery & 26 & $\begin{array}{l}80 \mathrm{~g} \text { albumin in units of } 100 \mathrm{ml} 20 \% \\
\text { albumin on day of operation, } 20 \mathrm{~g} \\
\text { daily for next } 3 \text { days }\end{array}$ & No albumin & 4 days & 0 & 2 \\
\hline Prien et $\mathrm{al}^{26}$ & Surgery & 12 & $\begin{array}{l}20 \% \text { albumin to maintain central } \\
\text { venous pressure at preoperative level }\end{array}$ & Ringer's lactate & Unspecified & 0 & 2 \\
\hline Boldt et al ${ }^{8}$ & Surgery & 30 & $5 \%$ albumin & No albumin & 1 day & 0 & 3 \\
\hline$\overline{\text { McNulty et al }{ }^{22}}$ & Surgery & 28 & $5 \%$ albumin & Isotonic crystalloid & Unspecified & Not known & 2 \\
\hline Woods et al ${ }^{36}$ & Surgery & 69 & Albumin supplementation & No supplementation & To discharge & 1 & 1 \\
\hline Pockaj et al ${ }^{25}$ & $\begin{array}{l}\text { Vascular leak } \\
\text { syndrome }\end{array}$ & 107 & $5 \%$ albumin in $0.9 \% \mathrm{NaCl}$ & $0.9 \% \mathrm{NaCl}$ & Unspecified & 0 & 2 \\
\hline Tølløfsrud et al ${ }^{32}$ & Surgery & 20 & $4 \%$ albumin when fluid required & Ringer's acetate & 48 hours & 1 & 3 \\
\hline Woittiez et al ${ }^{34}$ & Surgery & 31 & $20 \%$ albumin & $0.9 \% \mathrm{NaCl}$ & Unspecified & 12 & 3 \\
\hline \multicolumn{8}{|l|}{ Burns } \\
\hline Jelenko et al ${ }^{18}$ & Burns & 14 & $\begin{array}{l}\text { Hypertonic crystalloid with } 12.5 \mathrm{~g} / \mathrm{l} \\
\text { albumin }\end{array}$ & Ringer's lactate & 5 days & 3 & 2 \\
\hline Goodwin et al ${ }^{14}$ & Burns & 79 & $2.5 \%$ albumin in Ringer's lactate & Ringer's lactate & To discharge & 14 & 2 \\
\hline Greenhalgh et al ${ }^{15}$ & Burns & 70 & $\begin{array}{l}25 \% \text { albumin to maintain serum } \\
\text { levels between } 2.5 \text { and } 3.5 \mathrm{~g} / \mathrm{dl}\end{array}$ & $\begin{array}{l}\text { No albumin unless levels dropped } \\
\text { below } 1.5 \mathrm{~g} / \mathrm{dl}\end{array}$ & To discharge & 10 & 3 \\
\hline \multicolumn{8}{|l|}{ Hypoproteinaemia } \\
\hline Bland et al ${ }^{7}$ & Hypoproteinaemia & 27 & $25 \%$ albumin $8 \mathrm{ml} / \mathrm{kg}$ & $5 \%$ glucose $8 \mathrm{ml} / \mathrm{kg}$ & Unspecified & 5 & 2 \\
\hline Nilsson et a $\left.\right|^{24}$ & $\begin{array}{l}\text { Hypoalbuminaemia } \\
\text { (postoperative) }\end{array}$ & 59 & $\begin{array}{l}20-25 \mathrm{~g} \text { albumin/day for } 3 \text { days } \\
\text { starting day after operation }\end{array}$ & No supplemental albumin & To discharge & 1 & 3 \\
\hline Brown et al ${ }^{10}$ & Hypoalbuminaemia & 67 & TPN with added albumin & No supplemental albumin & To discharge & 10 & 1 \\
\hline Foley et a $\left.\right|^{11}$ & Hypoalbuminaemia & 40 & $\begin{array}{l}\text { TPN with added albumin }(25-50 \mathrm{~g} / \text { day } \\
25 \% \text { albumin) }\end{array}$ & No supplemental albumin & To discharge & 13 & 1 \\
\hline Kanarek et $\mathrm{al}^{19}$ & Hypoalbuminaemia & 24 & TPN with added albumin & No supplemental albumin & Unspecified & 5 & 3 \\
\hline Wojtysiak et al $^{35}$ & Hypoalbuminaemia & 30 & TPN with added albumin & No supplemental albumin & 5 days & 0 & 1 \\
\hline Greenough et al ${ }^{16}$ & $\begin{array}{l}\text { Hypoalbuminaemic sick } \\
\text { preterm infants }\end{array}$ & 40 & $\begin{array}{l}20 \% \text { salt-poor albumin } 5 \mathrm{ml} / \mathrm{kg} \text { with } \\
\text { maintenance fluids }\end{array}$ & $5 \mathrm{ml} / \mathrm{kg}$ maintenance fluid placebo & $\begin{array}{l}24 \text { hours after } \\
\text { infusion }\end{array}$ & 10 & 3 \\
\hline Golub et al ${ }^{13}$ & Hypoalbuminaemia & 219 & $\begin{array}{l}37.5 \mathrm{~g} / \text { day albumin until serum } \\
\text { albumin }>3.0 \mathrm{~g} / \mathrm{dl}\end{array}$ & No supplemental albumin & To discharge & 18 & 3 \\
\hline Rubin et al ${ }^{29}$ & Hypoalbuminaemia & 36 & TPN with added albumin & No supplemental albumin & To discharge & 3 & 3 \\
\hline
\end{tabular}

TPN=Total parenteral nutrition. *Allocation concealment: 1 =inadequate, $2=$ unclear, $3=$ adequate. 
not extract data on time to death. If a report did not include the numbers of deaths in each group, we sought these data from the authors. Two reviewers independently extracted the data, and any disagreements were resolved by discussion.

\section{Data analysis and statistical methods}

We used the Mantel-Haenszel method to calculate relative risks, risk differences, and 95\% confidence intervals for death for each trial on an intention to treat basis using RevMan (Review Manager) statistical software. When there are no events in one group the software adds 0.5 to each cell of the $2 \times 2$ table. We tested heterogeneity between trials using $\chi^{2}$ tests, with $\mathrm{P} \leqslant 0.05$ indicating significant heterogeneity. As long as statistical heterogeneity did not exist, we used a fixed effects model to calculate summary relative risks and $95 \%$ confidence intervals.

To examine the extent to which the results of the meta-analyses may have been biased as a result of the selective inclusion of randomised trials with positive findings (publication and other selection bias), we prepared a funnel plot and used the regression approach to assessing funnel plot asymmetry proposed by Egger et al. $^{6}$ We used the log odds ratio in the funnel plot because this is the measure that is used in the regression test of funnel plot asymmetry as described by Egger et al. Using simple unweighted linear regression, we regressed the standard normal deviate (defined as the log odds ratio divided by its standard error) against the estimate's precision (defined as the inverse of the standard error). The larger the deviation of the intercept of the regression line from zero, the greater the asymmetry and the more likely it is that the meta-analysis will yield biased estimates of effect. As suggested by Egger et al, we considered $\mathrm{P}<0.1$ to indicate significant asymmetry.

\section{Results}

We identified a total of 32 randomised controlled trials that met the study's inclusion criteria. ${ }^{7-38}$ The table shows details of these trials. Mortality data were available either from the published report or on contact with the authors in 30 of these trials. The two trials for which mortality data could not be obtained included a total of 42 randomised patients, comprising $3 \%$ of the total number of randomised patients in all trials meeting our inclusion criteria. ${ }^{22} 31$ One of the trials was an unpublished trial registered in the Medical Editors' Trial Amnesty, and we obtained further details, including data on mortality, directly from the trialist. In six trials there were no deaths in either the intervention or comparison groups. ${ }^{8} 1223252635$

The trial by Lucas et al was reported in five publications. ${ }^{21}{ }^{39-42}$ An early report gave the mortality data for 52 randomised patients, 27 allocated to receive albumin and 25 allocated to receive no albumin. ${ }^{21}$ Subsequent publications indicated that recruitment to the trial continued until 94 patients were randomised Mortality data for all the 94 patients were not published, nor were they available on contact with the author. Consequently, we present the outcome data for the 52 patients.

Of the 24 trials in which one or more deaths occurred in either the intervention or control groups,

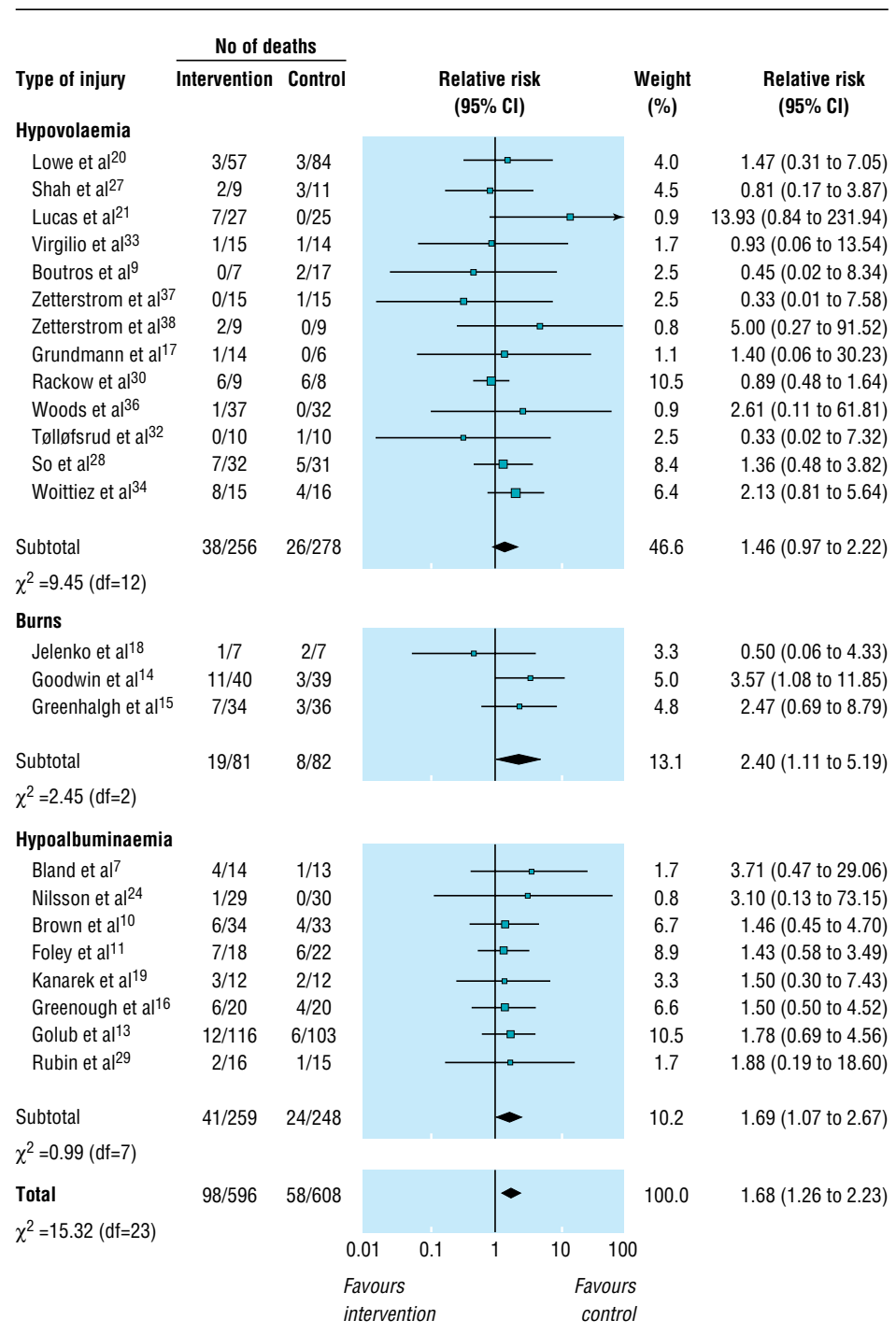

Fig 1 Fixed effects model of relative risks (95\% confidence interval) of death associated with intervention (fluid resuscitation with albumin or plasma protein fraction) compared with control (no albumin or plasma protein fraction or resuscitation with a crystalloid solution) in critically ill patients

13 included a method of allocation concealment that would be expected to reduce the risk of foreknowledge of treatment allocation (pharmacy controlled randomisation or serially numbered sealed opaque envelopes). In seven trials this was unclear, and in four trials concealment was inadequate (table).

In each of the patient categories the risk of death in the albumin treated group was higher than in the comparison group (fig 1). For hypovolaemia the relative risk of death after albumin administration was 1.46 (95\% confidence interval 0.97 to 2.22), for burns the relative risk was 2.40 (1.11 to 5.19), and for hypoalbuminaemia the it was 1.69 (1.07 to 2.67 ). There was no significant heterogeneity either between or within the groups of trials, or overall $\left(\chi^{2}=15.32\right.$, $\mathrm{df}=23, \mathrm{P}>0.2)$. The pooled relative risk of death with albumin administration was 1.68 (1.26 to 2.23).

There was no significant heterogeneity in the risk difference for mortality $\left(\chi^{2}=36.69, \mathrm{df}=29, \mathrm{P}>0.1\right)$. The pooled difference in the risk of death with albumin was $6 \%$ (95\% confidence interval 3\% to $9 \%)$. 


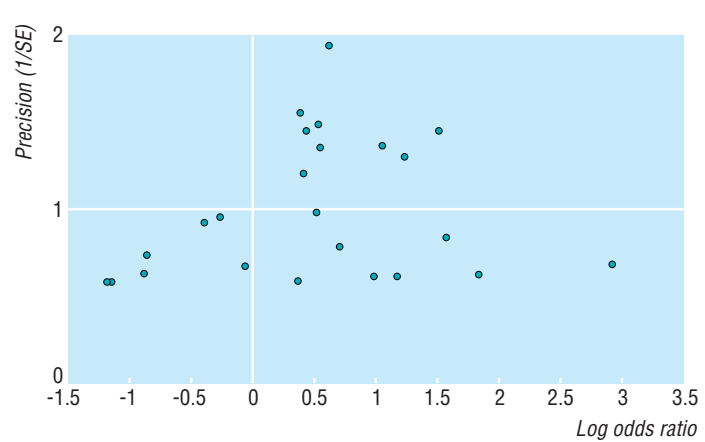

Fig 2 Funnel plot for the 24 trials in which deaths occurred and that were used in systematic review

Figure 2 shows a funnel plot for the 24 trials in which deaths occurred. There was no clear evidence of asymmetry, and the regression approach to funnel plot asymmetry yielded an intercept of -0.39 and $\mathrm{P}=0.33$, indicating no statistical evidence of selection bias.

We repeated the analyses for the 13 trials with deaths in which allocation concealment was adequate. ${ }^{13} 151619202427-2932343738$ For hypovolaemia the relative risk of death with albumin administration was 1.39 (0.80 to 2.40), for burns the relative risk was 2.47 (0.69 to 8.79 ), and for hypoalbuminaemia it was 1.71 (0.92 to 3.18). There was no substantial heterogeneity between the trials in the various categories $\left(\chi^{2}=4.42\right.$, $\mathrm{df}=12, \mathrm{P}>0.2)$, and the pooled relative risk of death with albumin administration was 1.61 (1.09 to 2.38). Thus, restricting the analyses to the adequately concealed trials had almost no effect on the relative risks in each group or overall.

\section{Discussion}

We found no evidence that albumin reduced mortality and a strong suggestion that it might increase the risk of death in patients with hypovolaemia, burns, or hypoproteinaemia. Overall, the risk of death in patients treated with albumin was $6 \%(95 \%$ confidence interval $3 \%$ to $9 \%$ ) higher than in patients not given albumin.

\section{Limitations of study}

Mortality was selected as the outcome measure in this systematic review for several reasons. In the context of critical illness, death or survival is a clinically relevant outcome that is of immediate importance to patients, and data on death are reported in nearly all studies. Furthermore, one might expect that mortality data would be less prone to measurement error or biased reporting than would data on pathophysiological outcomes. The use of a pathophysiological end point as a surrogate for an adverse outcome assumes a direct relationship between the two, an assumption that may sometimes be inappropriate. Finally, when trials collect data on a number of physiological end points, there is the potential for bias due to the selective publication of end points showing striking treatment effects. Because we obtained mortality data for all but two of the included trials, the likelihood of bias due to selective publication of trial outcomes is minimal. We examined mortality from all causes because the attribution of cause of death in critically ill patients, many of whom may have multiorgan failure, can be problematic and may be prone to bias. Length of follow up was not specified in many of the trials, but when these data were available, follow up was for the first week or until hospital discharge.

Although publication bias is a potent threat to the validity of systematic reviews, it is unlikely to have had an important impact in this study. There was no evidence of funnel plot asymmetry on visual inspection, and there was no statistical evidence of asymmetry from linear regression analysis.

In some of the trials included in this review allocation concealment was inadequate or unclear. As a result, it is possible that more severely ill patients were preferentially allocated to albumin treated groups, which could account for the increased mortality in these groups. Nevertheless, when we repeated the analyses for only those trials in which the method of allocation concealment would be expected to reduce the risk of foreknowledge of allocation, the point estimates were almost identical.

\section{Implications of results}

To what extent are the results of this review of 30 relatively small randomised trials of albumin administration generalisable to clinical practice? We believe that this is a matter for judgment by the responsible clinician faced with an individual patient. ${ }^{43}$ However, the advantage of an overview such as ours is that, since it includes many studies, the results are based on a wide range of patients. Because the results were consistent across the studies, they might reasonably be taken to apply to this wide variety of patients. ${ }^{43}$ Moreover, the evidence that we have brought together is, as far as we can ensure, the totality of the available randomised evidence for the use of albumin in hypovolaemia, burns, and hypoalbuminaemia, the indications for which albumin is currently licensed.

Is there a plausible mechanism by which human albumin might increase mortality? Albumin is used in hypovolaemia and hypoalbuminaemia because it is believed to be effective in replacing volume and supporting colloid oncotic pressure. ${ }^{44}$ However, albumin is also believed to have anticoagulant properties, inhibiting platelet aggregation and enhancing the inhibition of factor Xa by antithrombin III. ${ }^{44}$ Such anticoagulant activity might be detrimental in critically ill patients, particularly those with haemorrhagic hypovolaemia. Furthermore, albumin has been shown to distribute across the capillary membrane, a process that is accelerated in critically ill patients. ${ }^{45}$ It has been suggested that increased leakage of albumin into the extravascular spaces might reduce the oncotic pressure difference across the capillary wall, making oedema more likely. ${ }^{45}$

\section{Conclusions}

Because this review was based on relatively small trials in which there were only a small number of deaths the results must be interpreted with caution. Nevertheless, we believe that a reasonable conclusion from these results is that the use of human albumin in the management of critically ill patients should be reviewed. A strong argument could be made that human albumin should not be used outside the context of a properly concealed and otherwise rigorously conducted randomised controlled trial with 
Key messages

- Human albumin solution has been used in the treatment of critically ill patients for over 50 years

- Currently, the licensed indications for use of albumin are emergency treatment of shock, acute management of burns, and clinical situations associated with hypoproteinaemia

- Our systematic review of randomised controlled trials showed that, for each of these patient categories, the risk of death in the albumin treated group was higher than in the comparison group

- The pooled relative risk of death with albumin was $1.68(95 \%$ confidence interval 1.26 to 2.23$)$ and the pooled difference in the risk of death was $6 \%(3 \%$ to $9 \%)$ or six additional deaths for every 100 patients treated

- We consider that use of human albumin solution in critically ill patients should be urgently reviewed

mortality as the end point. Until such data become available, there is also a case for a review of the licensed indications for albumin use.

This review will also be published in the Cochrane Library, where it will be regularly updated to take account of new data and comments on this version.

We thank the Intensive Care National Audit and Research Centre in London for help with identifying trials for this review and for their extensive hand searching. We thank A J Woittiez for providing unpublished trial data from the trial that was registered in the Medical Editors' Trial Amnesty. We thank Elizabeth Bryant, information officer at Centeon, and Martin O'Fobve, at Bio Products, for searching their databases for albumin trials. We thank Anne Greenough for re-examining individual patient records in order to provide data on mortality. We thank Iain Chalmers, Jos Kleijnen, Richard Peto, Dave Signorini, and David Yates for their comments on the manuscript

Contributors (listed alphabetically): Phil Alderson (UK Cochrane Centre) searched The Cochrane Controlled Trials Register for relevant trials, extracted the data from the trials, and commented on the paper. Frances Bunn (Institute of Child Health) searched the Cochrane Injuries Group Specialised Register for relevant trials, obtained copies of relevant papers, wrote to authors for further information on allocation concealment, and commented on the paper. Carol Lefebvre (UK Cochrane Centre) designed the search strategies for The Cochrane Controlled Trials Register and Embase, and searched these two databases for relevant trials. Leah $\mathrm{Li}$ (Institute of Child Health) did the funnel plot and the regression test of funnel plot asymmetry. Alain Li Wan Po (Centre for Evidence-Based Pharmacotherapy, University of Nottingham) helped to write the paper. Ian Roberts (Institute of Child Health) designed the protocol, extracted data from the trials, contacted authors for unpublished data, and wrote the paper. Gillian Schierhout proposed the study hypothesis and conducted preliminary searches of Medline, Embase, and BIDS Index to Scientific and Technical Proceedings.

Funding: The infrastructure of the Cochrane Injuries Group is supported by the NHS Research and Development Programme.

Conflict of interest: None.

1 Goldwasser P, Feldman J. Association of serum albumin and mortality risk. J Clin Epidemiol 1997;50:693-703.

2 ABPI compendium of data sheets and summaries of product characteristics 1998-99. London: Association of the British Pharmaceutical Industries, 1998.

3 McClelland DB. Human albumin solutions. BMJ 1990;300:35-7.

4 Medical Editors' Trial Amnesty, The Cochrane Controlled Trials Register. In: The Cochrane Library. Oxford: Update Software, 1998. Updated quarterly.
5 Schulz KF, Chalmers I, Hayes RJ, Altman DG. Dimensions of methodological quality associated with estimates of treatment effects in controlled trials. JAMA 1995;273:408-12.

6 Egger M, Davey Smith G, Schneider M, Minder C. Bias in meta-analyses detected by a simple graphical test. BMJ 1997;315:629-34.

7 Bland RD, Clarke TL, Harden LB. Rapid infusion of sodium bicarbonate and albumin into high-risk premature infants soon after birth: a controlled, prospective trial. Am J Obstet Gynecol 1976;124:263-7.

8 Boldt J, Knothe C, Zickmann B, Andres P, Dapper F, Hempelmann G. Influence of different intravascular volume therapies on platelet function in patients undergoing cardiopulmonary bypass. Anesth Analg 1993;76:1185-90.

9 Boutros AR, Ruess R, Olson L, Hoyt JL, Baker WH. Comparison of hemodynamic, pulmonary, and renal effects of use of three types of fluids after major surgical procedures on the abdominal aorta. Crit Care Med 1979;7:9-13.

10 Brown RO, Bradley JE, Bekemeyer WB, Luther RW. Effect of albumin supplementation during parenteral nutrition on hospital morbidity. Crit Care Med 1988;16:1177-82.

11 Foley EF, Borlase BC, Dzik WH, Bistrian BR, Benotti PN. Albumin supplementation in the critically ill: a prospective randomised trial. Arch Surg 1990;125:739-49.

12 Gallagher JD, Moore RA, Kerns D, Jose AB, Botros SB, Flicker S, et al. Effects of colloid or crystalloid administration on pulmonary extravascular water in the postoperative period after coronary artery bypass grafting. Anesth Analg 1985;64:753-8.

13 Golub R, Sorrento JJ Jr, Cantu R Jr, Nierman DM, Moideen A, Stein HD. Efficacy of albumin supplementation in the surgical intensive care unit: a prospective, randomized study. Crit Care Med 1994:22:613-9.

14 Goodwin CW, Dorethy J, Lam V, Pruitt BA Jr. Randomized trial of efficacy of crystalloid and colloid resuscitation on hemodynamic response and lung water following thermal injury. Ann Surg 1983;197:520-31

15 Greenhalgh DG, Housinger TA, Kagan RJ, Rieman M, James L, Novak S, et al. Maintenance of serum albumin levels in paediatric burn patients: a prospective, randomized trial [with discussion]. J Trauma 1995;39:67-73. (Discussion 1995:39:73-4.)

16 Greenough A, Emery E, Hird MF, Gamsu HR. Randomised controlled trial of albumin infusion in ill pre-term infants. Eur $J$ Pediatr $1993 ; 152: 157-9$

17 Grundmann R, Meyer H. The significance of colloid osmotic pressure measurement after crystalloid and colloid infusions. Intensive Care Med 1982;8:179-86.

18 Jelenko C 3rd, Williams JB, Wheeler ML, Callaway BD, Fackler VK, Alber CA, et al. Studies in shock and resuscitation. I: Use of a hypertonic, albumin-containing, fluid demand regimen (HALFD) in resuscitation. albumin-containing, fluid dem
Crit Care Med 1979;7:157-67.

19 Kanarek KS, Williams PR, Blair C. Concurrent administration of albumin with total parenteral nutrition in sick new-born infants. J Parenter Enteral Nutr 1992;16:49-53.

20 Lowe RJ, Moss GS, Jilek J, Levine HD. Crystalloid vs colloid in the aetiology of pulmonary failure after trauma: a randomized trial in man. Surgery 1977:1:676-83.

21 Lucas CE, Weaver D, Higgins RF, Ledgerwood AM, Johnson SD, Bouwman DL. Effects of albumin versus non-albumin resuscitation on plasma volume and renal excretory function. J Trauma 1978;18:565-70.

22 McNulty SE, Sharkey SJ, Asam B, Lee JH. Evaluation of STAT-CRIT hematocrit determination in comparison to coulter and centrifuge: the effects of isotonic hemodilution and albumin administration. Anesth Analg 1993;76:830-4

23 Nielsen OM, Engell HC. Extra-cellular fluid volume and distribution in relation to changes in plasma colloid osmotic pressure after major surgery. A randomised study. Acta Chir Scand 1985;151:221-5.

24 Nilsson E, Lamke O, Liljedahl SO, Elfstrom K. Is albumin therapy worthwhile in surgery for colorectal cancer? Acta Chir Scand 1980:146:619-29.

25 Pockaj BA, Yang JC, Lotze MT, Lange JR, Spencer WF, Steinberg S, et al. A prospective randomized trial evaluating colloid versus crystalloid resuscitation in the treatment of the vascular leak syndrome associated with interleukin-2 therapy. J Immunother 1994;15:22-8.

26 Prien T, Backhaus N, Pelster F, Pircher W, Bunte H, Lawin P. Effect of intraoperative fluid administration and colloid osmotic pressure on the formation of intestinal edema during gastrointestinal surgery. J Clin Anesth 1990;2:317-23.

27 Shah DM, Browner BD, Dutton RE, Newell JC, Powers SR. Cardiac outpu and pulmonary wedge pressure. Arch Surg 1977;112:1161-4.

28 So KW, Fok TF, Ng PC, Wong WW, Cheung KL. Randomised controlled trial of colloid or crystalloid in hypotensive pre-term infants. Arch Dis Child 1997;76:F43-6.

29 Rubin H, Carlson S, DeMeo M, Ganger D, Craig R. Randomized, double-blind study of intravenous human albumin in hypoalbuminaemic patients receiving total parenteral nutrition. Crit Care Med 1997·95:249-52.

30 Rackow EC, Falk JL, Fein IA, Siegel JS, Packman MI, Haupt MT, et al. Fluid resuscitation in circulatory shock: a comparison of the cardiorespiratory effects of albumin, hetastarch, and saline solutions in patients with hypovolemic and septic shock. Crit Care Med 1983;11:839-50.

31 Skillman JJ, Restall DS, Salzman EW. Randomized trial of albumin vs electrolyte solutions during abdominal aortic operations. Surger 1975;78:291-303.

32 Tølløfsrud S, Svennevig JL, Breivik H, Kongsgaard U, Øzer M, Hysing F et al. Fluid balance and pulmonary functions during and after coronary artery bypass surgery: Ringer's acetate compared with dextran, polygeline, or albumin. Acta Anaesthesiol Scand 1995;39:671-7.

33 Virgilio RW, Rice CL, Smith DE, James OR, Zarins CK, Hobelmann CF, et al. Crystalloid vs. colloid resuscitation: is one better? A randomized clinical study. Surgery 1979;85:129-39.

34 Woittiez AJ. Restoration of colloid osmotic pressure in post operative intensive care patients. A randomised placebo controlled trial with albu- 
men 20\% and hydroxy-ethyl starch. In: Medical Editors' Trial Amnesty, The Cochrane Controlled Trials Register. In: The Cochrane Library. Issue 2. Oxford: Update Software, 1998. Updated quarterly.

35 Wojtysiak SL, Brown RO, Roberson D, Powers DA, Kudsk KA. Effect of hypoalbuminaemia and parenteral nutrition on free water excretion and electrolyte-free water resorbtion. Crit Care Med 1992;20:164-9.

36 Woods MS, Kelley H. Oncotic pressure, albumin and ileus: the effect of albumin replacement on postoperative ileus. Am Surg 1993;59:758-63.

37 Zetterstrom H, Hedstrand U. Albumin treatment following major surgery. I: Effects on plasma oncotic pressure, renal function and peripheral oedema. Acta Anaesth Scand 1981;25:125-32.

38 Zetterstrom H. Albumin treatment following major surgery. II: Effects on postoperative lung function and circulatory adaptation. Acta Anaesth Scand 1981;25:133-41.

39 Weaver DW, Ledgerwood AM, Lucas CE, Higgins R, Bouwman DL, Johnson SD. Pulmonary effects of albumin resuscitation for severe hypovolaemic shock. Arch Surg 1978;113:387-92.
40 Johnson SD, Lucas CE, Gerrick SJ, Ledgerwood AM, Higgins RF. Altered coagulation after albumin supplements for treatment of oligaemic shock. Arch Surg 1979;114:379-83.

41 Lucas CE, Bouwman DL, Ledgerwood AM, Higgins R. Differential serum protein changes following supplemental albumin resuscitation for hypovolaemic shock. J Trauma 1980;20:47-51.

42 Clift DR, Lucas CE Ledgerwood AM, Sardesai V, Kithier K, Grabow D. The effect of albumin resuscitation for shock on the immune response to tetanus toxoid.J Surg Res 1982;32:449-52.

43 Oxman A, Cook D, Guyatt GH for the Evidence-based Medicine Working Group. User's guides to the medical literature. VI: How to use an overview. JAMA 1994;272:1367-71.

44 Soni N. Wonderful albumin? BMJ 1995;310:887-8.

45 Fleck A, Raines G, Hawker F, Trotter J, Wallace P, Ledingham I, et al. Increased vascular permeability: a major cause of hypoalbuminaemia in disease and injury. Lancet 1985;i:781-4.

(Accepted 1 July 1998)

\section{Why albumin may not work}

Science commentary
Starling's principle is often represented as the leakage of fluids from the arterial end of capillaries, where the hydrostatic pressure is greater than the oncotic pressure (derived from the plasma proteins), and the reabsorption of fluid into the venous end, where the oncotic pressure exceeds the hydrostatic pressure. A small excess of fluid in the interstitial space-when filtration from the capillaries is greater than reabsorption-is dealt with by lymphatic drainage from the interstitial space. The rationale for giving albumin solutions rather than crystalloid solutions in cases of hypovolaemic shock is that fluid reabsorption from the interstitial space is enhanced, and fluid therefore remains in the vascular system for longer.

But in recent years the assumed reabsorption of fluid at the venous end of capillaries has been challenged. There is now good evidence to show that, except in the gut and the renal circulation, there is no sustained reabsorption of fluid at the venous end of capillaries. Instead, there is a small constant level of filtration from the capillaries, restrained by the osmotic pressure of the plasma proteins. In some rare circumstances-for example, in hypovolaemic shockthere is a transient reabsorption of fluid, but this lasts for only a few minutes and it amounts to an "internal transfusion" of about $500 \mathrm{ml}$ of fluid over 15 minutes.

The production of life threatening pulmonary oedema begins when the loss of protein and fluid from the blood vessels exceeds the volume of fluid that can be drained from the interstitial space by the lymphatics. In some disease states or when tissue is damaged, as in severe burns, the capillary walls become very much more permeable under the influence of direct cellular damage and from inflammatory mediators. The filtration of fluids, together with proteins, out into the interstitial space is greatly increased and cannot be matched by lymphatic drainage. The filtration rate may be further increased by a fall in the hydrostatic pressure in the interstitial space as a result of tissue damage, so that even more fluid is sucked out of the capillaries.

Conventionally, colloids such as albumin are administered to these patients in an attempt to maintain their intravascular volume, but because of the increased permeability of the vessels, the albumin solution becomes much less effective in maintaining plasma volume than in healthy individuals who have normal vessel permeability. Thus the rationale for administering albumin solutions becomes much less clear. In disease states such as the nephrotic syndrome, for example, there is new evidence to show that protein is lost not only from the renal circulation owing to greater permeability of the renal vessels, but also from the rest of the systemic circulation. This being the case, it is difficult to see how the administration of albumin could ever replace the deficit without causing further problems.

Abi Berger-Science editor, BMJ

\section{A memorable patient "I got no counselling"}

Examining war pensioners can provide an opportunity to listen, unstressed by the constraints imposed by active disease or the length of the appointment. Occasionally, you are exposed to tales of immense courage or distress recounted with characteristic British understatement.

The gentle former bank messenger described how his warship was ordered alongside a burning merchant ship which was packed full of ammunition. The inevitable happened and the pensioner found himself floating in the water. He was taken ashore to a hospital and after four weeks of convalescence his bed was required and he was sent back to his ship on "light duties."

What had these "light" duties consisted of? "Well by then," he recounted, "our ship had been beached and we had to go below decks to bring out the bodies and sew them into canvas hammocks. When the padre found out what we were doing it was stopped, but, you know doc, I got no counselling," he added with a wry smile.

Close to tears, he described his visit to bereaved parents whose only son he had taught to wash and iron his own clothes. Amazingly, my patient had no subsequent experience of flashbacks or nightmares. But what he did have was a strong feeling of the shared experience of working with fellow survivors and their relatives to lay to rest shipmates with whom he had sailed and fought. The existence of a common enemy allowed comfort to be obtained from even this gruesome task, spared from the modern distraction of searching through a sequence of events for someone to blame and the possibility of eventual financial compensation.

Jim Ford, senior medical officer, Department of Health, Leeds 